\title{
A força dos pensamentos, o fedor do sangue. Hematologia e gênero na Amazônia'
}

\author{
Luisa Elvira Belaunde \\ Universidade Nacional Mayor de San Marcos (Lima, Peru)
}

RESUMO: Este artigo estabelece as bases para uma hematologia amazônica com a finalidade de compreender o significado do sangue com respeito a gênero, conhecimento e cosmologia. Baseando-se na crítica da teoria do patriarcado elaborada por Overing e em seu estudo das concepçôes piaroa sobre a menstruação, este artigo explora comparativamente as idéias de vários povos amazônicos sobre como os espíritos, os pensamentos e a força se transformam em corpos diferenciados por gênero. Defende que o fluxo do sangue é concebido como uma relação, já que transporta conhecimentos a todas as partes do corpo, unindo, e ao mesmo tempo diferenciando, homens e mulheres, e constituindo o eixo central da existência de uma pessoa ao longo de seu ciclo de vida. Por meio do estudo das práticas de resguardo, dieta e reclusão, mostra que a manipulação do sangue ocupa um lugar central na saúde amazônica. Sangrar é uma prerrogativa feminina e a lembrança incorporada nas mulheres sobre o incesto primordial entre Lua e sua irmã, que fundamenta a memória e o parentesco humanos. No entanto, os homens também "parecem mulheres" quando ficam sob a vingança do sangue de seus inimigos, assim como as mulheres sob a vingança de Lua. $\mathrm{O}$ sangrar põe a fertilidade em movimento, abrindo a comunicação entre o tempo cotidiano e outros espaços-tempos cosmológicos, expondo ambos os gêneros ao perigo da multiplicidade transformacional, à alienação e à morte. Sua relação com o xamanismo é, portanto, fundamental.

PALAVRAS-CHAVE: xamanismo amazonense, menstruação, incesto, sangue, gênero. 
Belaunde, L. E. A força dos pensamentos, o fedor do sangue...

Em 1986² Joanna Overing argumentou que, se o estudo das práticas menstruais amazonenses quisessem evitar cair na obviedade de sentenciar as mulheres ao banco dos perdedores no jogo de prestígio contra os homens, deveria distanciar-se de suposiçôes teóricas sobre o patriarcalismo e beber diretamente na fonte dos entendimentos indígenas sobre egos autônomos e corpos feitos por pensamentos. Sua descrição dos colares piaroa como "contas de conhecimento sobre a menstruação", trazidos de caixas de cristal celestiais e usados pelas mulheres sobre e "dentro" de seus corpos, tornou-se um clássico da literatura amazonense, estabelecendo um marco no estudo das teorias indígenas sobre corporalidade e pensamento. Beleza, habilidades, fertilidade, produtos e filhos de homens e mulheres, diz ela, são os seus pensamentos: são o resultado de suas capacidades de conhecimento, cuidadosamente incorporadas dos deuses e postas em prática de forma autônoma em seu trabalho.

Para os Piaroa, toda capacidade cultural é bruxaria, incluindo a menstruação, que é considerada junto com a caça, a pesca e a feitiçaria como conhecimento transcendente adquirido por meio do maripa teau, ou "liçōes de bruxaria”. (Overing, 1986, p. 147)

Na classificação piaroa, toda criação pela qual um indivíduo é responsável é considerada seu a'kwa', ou "pensamento". Portanto, os produtos do trabalho de cada um, o filho de uma pessoa e uma transformação pela feitiçaria, por exemplo, a transformação do bruxo em onça ou sucuri, são considerados "pensamentos" daquela pessoa. (Id., p. 148)

Vinte anos depois, novas etnografias nos permitem compor um quadro transcultural do que é o sangue para os povos da Amazônia e explorar por que a administração do seu fluxo é crucial para ambos os gêneros. Aqui, lanço as bases para uma hematologia amazonense, pretendendo 
Revista de Antropologia, São Paulo, USP, 2006, v. 49 No 1.

decifrar o significado do sangue com relação a gênero, conhecimento e cosmologia. Minha atenção se volta para temas como a corporificação e a atribuição de gênero aos espíritos, o pensamento e a força do sangue, a administração do sangue por meio de práticas de resguardo e os processos de "troca de pele" mobilizados pela sangria e pelo cheiro do sangue.

Apesar das abordagens inspiradoras de Overing, o estudo da menstruação não alcançou o palco central dos debates teóricos sobre a Amazônia. Na verdade, o mesmo pode ser dito do gênero, uma categoria de análise não muito popular entre os amazonistas (Descola, 2001). Espero que os argumentos aqui reunidos possam contribuir para reverter essa situação. A maioria das etnografias recentes do xamanismo perspectivista e da cosmologia ressaltam a multiplicidade transformadora do corpo concebido como uma "pele" ou "roupa” removível (Viveiros de Castro, 1996; ver também Rosengren, Santos-Granero, Storrie e Lagrou, neste volume). Por outro lado, algumas etnografias recentes, e não tão recentes, também examinam concepções indígenas do sangue e suas ligações com a noção de pessoa (C. Hugh-Jones, 1979; Albert, 1985; Brown, 1985; Crocker, 1985; Lima, 1995; Reichel-Dolmatoff, 1997; Karadimas, 1997; Goulard, 1998; Surrallés, 1999; Guzmán, 1997; Conklin, 2001a; Gonçalves, 2001; Belaunde, 2001; Rodgers, 2002; Garnelo, 2003; Colpron, 2004). É necessário articular as noçōes amazônicas do sangue com visões atuais sobre perspectivismo para poder posicionar o gênero entre os debates teóricos sobre cosmologia. De fato, nossas abordagens da cosmologia podem perder seus objetivos, a menos que lidemos com a questão do sangue. Evidência etnográfica abundante demonstra que, entre uma diversidade de grupos culturais, o sangue é concebido como um fluido que corporifica e atribui gênero às pessoas, ao pensamento e à força, transportando conhecimento a todas as partes do corpo. O sangue opera tanto dentro do corpo de uma pessoa quanto fora dele. $\mathrm{O}$ sangue vertido pelas pessoas tem um efeito transformador 
Belaunde, L. E. A força dos pensamentos, o fedor do sangue...

sobre a experiência vivida e abre as cortinas da comunicação e da percepção que geralmente separam a experiência cotidiana da experiência de outros tempos-espaços cosmológicos. Seu entrelaçamento com o xamanismo é, portanto, fundamental. Por toda a Amazônia, sangrar é a "troca de pele/corpo" par excellence, e são as mulheres quem mais evidentemente fazem com que isso aconteça, em suas regras e no nascimento da criança.

Com o objetivo de apreender o que é o sangue para os povos da Amazônia, recorro novamente à inspiração de Overing. No artigo mencionado acima, a autora (1986, p. 140) sugere que as relações de gênero, como quaisquer relações sociais, são articuladas em torno de uma "noção filosófica sobre o que significa ser diferente e ser igual", um princípio pan-amazonense que define a mistura adequada de coisas diferentes e iguais para a criação da existência social. Esse princípio destaca a concepção amazonense de reciprocidade como "uma relação de igualdade e de diferença" operante em todas as dimensões, do cotidiano à cosmologia (Overing Kaplan, 1981). A mistura de diferença e semelhança mantém todas as relações de reciprocidade, incluindo relaçóes entre pessoas do mesmo gênero e parceiros de gênero diferente. Homens e mulheres estão unidos em ligações e transações recíprocas na irmandade, na sedução, no casamento e em outros aspectos rituais. Portanto, suas relações também respondem a uma dinâmica de igualdade dentro da diferença, e diferença dentro da igualdade.

Antropólogos de diversas abordagens teóricas incorporaram a sugestão de Overing, mas o fizeram basicamente com relação às associações masculinas de afinidade, de caráter político e cosmológico. Com relação às associações entre homens e mulheres, a pesquisa em sua maioria ficou confinada aos alunos da autora. Por exemplo, Gow (1991), McCallum (2001), Lagrou (1998) e Londoño Sulkin (2004) demonstraram consistentemente que as relações de gênero são tecidas por meio 
Revista de Antropologia, São Paulo, USP, 2006, v. 49 no 1.

de um entrelaçamento de processos de diferença e igualdade. Meu estudo de gênero airo-pai (Belaunde, 2001) é provavelmente o mais extremo, já que sustenta que homens e mulheres podem ser, dependendo de onde nos situamos, tanto da mesma espécie quanto de duas espécies diferentes. Entretanto, não de duas espécies humanas, mas sim duas espécies de pássaros. Gênero, portanto, permeia a cosmologia perspectivista airo-pai.

Do ponto de vista dos deuses airo-pai, os homens são japus (Icteribus $s p$.), pássaros carnívoros, cantores e tecedores de ninhos que ficam pendurados nos galhos das árvores. As mulheres são papagaios-verdes ( $\mathrm{Ama-}$ zona sp.), comedoras de sementes e formam seus ninhos em buracos abertos nos troncos das árvores. Portanto, cada gênero, ou melhor, cada espécie de pássaro, faz seu próprio ninho para criar seus filhotes, tendo também as próprias tecnologias materiais, seus alimentos, suas estratégias de defesa e o próprio entendimento das relações de poder e de gềnero dentro da sua espécie, quer dizer, dentro de seu gênero: os homens são filhos de seus pais, e as mulheres são filhas de suas mães. No entanto, essa diferenciação radical também destaca a igualdade existente entre os gêneros, já que tanto os homens quanto as mulheres têm as mesmas responsabilidades integrais com relação à criação de seus filhotes de mesmo gênero.

Inversamente, do ponto de vista dos vivos, homens e mulheres são um mesmo pai, "povo". Portanto, sua diferenciação se constrói baseada em sua semelhança. Alguns dias após o nascimento, a genitália das meninas é operada, e sua canihuë neanco - "pele/corpo escura" - das bordas de sua lábia menor é retirada, causando-lhes sangramento. As meninas têm o seu corpo aberto - como o ninho de um papagaio -, caso contrário ficarão ëmëje paiye, "parecem homens", ou seja, incapazes de menstruar ou dar à luz. A capacidade de verter sangue assim construída separa os gêneros, mas não de forma rígida ou definitiva. Diz-se que as mulheres 
Belaunde, L. E. A força dos pensamentos, o fedor do sangue...

"parecem homens" quando elas não apresentam sinais de sangue, ou seja, nem traços visíveis nem tampouco qualquer sinal do cheiro do sangue. Diz-se que os homens "parecem mulheres" quando eles apresentam sinais ou cheiro do seu próprio sangue ou do sangue de outras pessoas. Embora o sangramento seja em princípio definido como um atributo feminino, para ambos os gêneros, verter sangue leva a uma mudança de canihuë, "pele/corpo". Esse sangramento é necessário para a fertilidade e a renovação, mas ele também torna homens e mulheres vulneráveis ao ataque dos espíritos sedentos de sangue. Observar um período de resguardo, com dieta e reclusão, é a melhor forma de regular a dinâmica transformacional movimentada pelo sangramento e por seu cheiro.

Partindo da etnografia airo-pai para lançar as bases de uma hematologia amazonense, defendo que o sangue constitui o principal veículo para a igualdade de gêneros assim como para a diferença. O sangue é uma relação que tanto une quanto divide os seres humanos em homens e mulheres. De fato, uma variedade de etnografias mostra que o sangue é concebido como uma relação porque ele circula pelo corpo, pondo todas as suas partes em comunicação e enchendo-as de pensamento e força para a ação intencional. Ninguém expressa isso melhor do que Brown (1985) em sua introdução à mágica awajun (aguaruna), quando ele faz a Shajián Wajai's uma pergunta aparentemente trivial: "As pessoas pensam com suas cabeças ou com seus corações?”.

Ele bebeu de uma tigela de cerveja que sua esposa lhe entregou, e depois respondeu deliberadamente: "As pessoas que dizem que pensamos com nossas cabeças estão erradas porque pensamos com os nossos corações. O coração está conectado às veias, que levam os pensamentos no sangue através de todo o corpo. O cérebro está conectado apenas à espinha, certo? Então, se pensássemos com os nossos cérebros, nós só conseguiríamos movimentar nossos pensamentos até os nossos ânus! (Brown, 1985, p. 19) 
Revista de Antropologia, São Paulo, USP, 2006, v. 49 no 1.

Com senso de humor tipicamente amazonense, Shajián Wajai deixa claro que o sangue não é algo para ser constantemente derramado, mas sim movimentado através das veias atribuindo pensamento a todas as partes do corpo. O coração é o centro a partir do qual os pensamentos são impulsionados, alcançando todos os órgãos e permitindo que uma pessoa aja sobre o mundo em interação com outros. Comida, objetos, palavras, música, cheiros e crianças produzidos são manifestações da boa circulação dos pensamentos de uma pessoa, exteriorizados na realidade física por meio de seu trabalho habilidoso e esforçado. Em Awajun, assim como em muitas línguas amazonenses, o "pensamento" implica a noção de lembrar com compaixão aqueles que amamos e fazer algo para aliviar ou evitar a sua dor. ${ }^{3}$ Os pensamentos que circulam no sangue, portanto, se traduzem em trabalho e em cuidados efetivos entre os parentes.

Noções semelhantes são encontradas na maioria dos grupos culturais. Em Yine (Piro), giglenshinikanuta significa "memória, amor, pensamento e pensar sobre alguém". A memória dos cuidados recebidos de outros sustenta relações de parentesco reais, a experiência vivida e a história pessoal e do grupo, enquanto a carência de generosidade causa a decadência do parentesco (Gow, 1991, p. 150). Em Candoshi, a expressão característica magochino, "meu coração pensa", é bem traduzida por "meu coração pensa sobre alguém ou algo com relação a alguém", já que nossos pensamentos sempre pretendem o benefício efetivo de alguém que temos em mente, ou melhor, no coração (Surrallés, 1999, p. 128). Entre os Wari e os Airo-Pai, acredita-se que as pessoas preguiçosas, más e invejosas, que não estão dispostas a cuidar de outras, "não têm coração", já que elas "não sabem pensar" (Conklin, 2001a, p. 143; Belaunde, 2001, p. 107). Essa ausência de coração implica uma ausência de corpo, visto que as pessoas sem pensamento não exercem nenhuma habilidade corporal produtiva. Seus corpos no vale, "não têm valor", dizem os AiroPai em espanhol. Carecer de pensamento, carecer de corpo e carecer de 
Belaunde, L. E. A força dos pensamentos, o fedor do sangue...

parentesco, portanto, são coisas intimamente relacionadas - questão que freqüentemente se torna explícita na semântica amazonense, por exemplo entre os Sharanahua, segundo os quais, a expressão "meus parentes" significa literalmente "minha carne" (Siskind, 1973, p. 22).

Embora o coração de uma pessoa seja o centro do pensamento, isso não significa que ele monopoliza todos os processos. $\mathrm{O}$ pensamento pode também estar assentado sobre outras partes do corpo, mas o coração as reúne sob a batida e o fluxo unificadores do sangue. Pensar com o coração significa pensar como um todo fluido, e não em pedaços desconectados. Além disso, o centro do pensamento pode nem estar confinado a um órgão fisiológico definido. Entre os Kaxinawa, por exemplo, todas as partes do corpo são consideradas pensantes, já que todas recebem espíritos yuxin carregados no fluxo de sangue e na respiração, e moldados no corpo humano. Um corpo vivo é sustentado por suas capacidades de conhecimento e agenciamento e está continuamente aprendendo nessas interações com outros, já que se exterioriza nos produtos do trabalho. ${ }^{4}$ Por essa razão, uma pessoa inteiramente sábia, una haida haiyaki, é alguém cujo corpo inteiro é sábio, e que é trabalhadeira e generosa com conhecimento e produtos (Kensinger, 1995, p. 246; Lagrou, 1998, p. 78; McCallum, 2001, p. 5; Deshayes \& Keifenheim, 2003, p. 105).

Entre os Muinane, o centro do pensamento está alojado na "cesta de conhecimento", correspondendo à caixa toráxica, e é alimentado pela audição de palavras de conselho dos mais velhos e pelo consumo de alimentos espirituais, tais como tabaco e coca para os homens, e mandioca, pimentas e plantas de essências para as mulheres (Londoño Sulkin, 2004, p. 28). Entre os Macuna, üsi, um espírito vital ligado à respiração, reside no coração e combina com tüoiare, uma capacidade de aprendizagem baseada na audição e na imitação. Os pensamentos são gravados nos "ouvidos" e mantidos em diversos "bancos de pensamentos", um dos quais, no caso das mulheres, é alojado no útero, enquanto um dos 
Revista de Antropologia, São Paulo, USP, 2006, v. 49 no 1.

"bancos de pensamentos" dos homens é uma extensão dos seus corpos - um banco cerimonial de madeira utilizado para se sentar (Mahecha, 2004, p. 160). Entre os Wari, a fisiologia do coração está necessariamente ligada a afeto, digestão e respiração. $\mathrm{O}$ coração transforma a comida em sangue por intermédio da respiração. Quando uma pessoa faz um esforço físico, uma respiração mais profunda promove uma batida cardíaca mais forte, que por sua vez facilita a transformação da comida em sangue e circulação sangüínea fluida, que por sua vez leva à acumulação de gordura corporal e à resistência para continuar trabalhando e produzindo comida para si mesmo e para os parentes. Pessoas pensativas são trabalhadeiras, robustas e saudáveis, enquanto as preguiçosas, más e invejosas são magras e doentias. A tristeza também contrai o coração, impedindo a boa circulação e levando à perda de gordura e, eventualmente, à morte (Conklin, 2001a, p. 143).

O coração e o fluxo de sangue, portanto, aparecem como pivô da existência de uma pessoa em constante transformação através do seu ciclo de vida. Essa idéia é também proeminente no estudo revelador de Crocker (1985, p. 45) sobre a "hidráulica" dos Bororo, raka. O sangue e seus derivados, o sêmen e o leite, são raka, local da união dos bope, princípios de transformação orgânica, e dos aroe, os eternos nomes das almas reciclados por meio das geraçóes, mantendo todos os seres vivos com sua vitalidade espiritual. O fluxo do sangue conduz os nomes imortais das almas ao longo do curso irreversível da vida e da história social de uma pessoa, permitindo que essa pessoa aprenda, trabalhe e seja movida por apetites predatórios específicos do seu ser, gênero ou subjetividade. Como diz o autor, devido a seus sangues, homens caçam, mulheres coletam, pássaros voam e onças matam (id., p. 36).

O estudo de Crocker oferece os elementos-chave da hematologia amazonense, ressoando com diversas outras etnografias, que resumo como se segue. Os bebês nascem com pouco sangue. Por esse motivo, 
Belaunde, L. E. A força dos pensamentos, o fedor do sangue...

seus espíritos estão conectados de forma fraca a seus corpos, têm pouco conhecimento e podem facilmente ficar doentes e morrer. A conexão de seus espíritos aumenta com o aumento nos níveis de sangue, por meio da alimentação e da incorporação de nomes e capacidades das fontes espirituais. Ao longo da infância, a aprendizagem por meio da imitação e da audição acompanha as linhas do gênero da criança, culminando na puberdade, quando meninos e meninas atingem seu potencial máximo de sangue. Daí por diante, eles devem exercitar suas capacidades "copulando, fazendo trabalho físico, dançando e cantando" (id., p. 42). Em sua juventude, homens e mulheres têm sangue, conhecimento, resistência e apetites diferentes, e o sangue menstrual e pós-parto das mulheres representa uma ameaça à saúde dos homens, mudando seu fluxo sangüíneo. Em geral, as doenças são concebidas como um desequilíbrio de volume, velocidade, temperatura, cor, cheiro e/ou espessura do sangue de uma pessoa. Estados emocionais são também estados do sangue e podem terminar em enfermidades. A raiva, em particular, leva a uma aceleração e ao aquecimento do sangue, e deve ser tratada com cuidado. A observância de períodos de dieta e reclusão, incluindo abstinência sexual, é uma técnica de regulação do fluxo sangüíneo. O resguardo é observado individualmente por homens e mulheres e, até certo ponto, coletivamente por todos aqueles próximos a eles. ${ }^{5} \mathrm{O}$ sangue percorre gerações. Por meio de seus sangues e fluidos sexuais derivados, homens e mulheres transmitem a seus filhos suas características pessoais "físicas, morais e espirituais" (id., p. 109). O sangue também une aqueles que compartilham residência em círculos de apoio e vingança, em caso de ferimento e/ou morte de uma pessoa querida. À medida que o tempo passa, as pessoas que vivem juntas começam a compartilhar seus fluidos e se tornam parecidas. Com o envelhecimento, o sangue de ambos os gêneros enfraquece e as conexões de seus espíritos são atenuadas. Homens e mulheres perdem suas capacidades produtivas e seu impulso 
Revista de Antropologia, São Paulo, USP, 2006, v. 49 no 1.

predatório, o que se manifesta pela perda dos dentes. Finalmente, os ancestrais nunca brigam, nunca estão doentes, porque não têm sangue (id., p.117).

Etnografias recentes apresentam ligações novas e mais detalhadas entre sangue, gênero e conhecimento. Em seu estudo da noção de pessoa dos Kaxinawa, McCallum (2001, p. 5) argumenta que corpo e gênero são inseparáveis porque não existe corpo antes de gênero. $\mathrm{Na}$ verdade, "gênero é conhecimento corporificado". Dou prosseguimento a seu argumento demonstrando que a corporificação do conhecimento nas pessoas atribuídas de gênero caminha lado a lado com a atribuição de gênero ao sangue. Por exemplo, Guzmán (1997, p. 57) menciona o caso de um homem quichua canelo que recebeu transfusão de sangue após um acidente. Quando ele acordou, perguntou preocupado se tinha recebido o sangue de um homem ou de uma mulher. Porque ele considerava que, se tivesse recebido sangue de uma mulher, ele teria incorporado aspectos daquela mulher. $\mathrm{O}$ que diferencia o sangue de um homem do sangue de uma mulher não é a essência de gênero imutável, mas sim as experiências pessoais do homem ou da mulher: o que eles aprenderam, comeram, fizeram, e com quem; os poderes e nomes espirituais que recebem, e de quem; a companhia que compartilharam e os sonhos que tiveram. Todas essas experiências vividas são incorporadas ao sangue, diferenciando homens e mulheres, bem como diferenciando uma pessoa de outra de forma única. Diferenças entre mulheres, e entre homens, permanecem altamente significativas e não podem ser reduzidas a identidades estáticas de gênero predefinidas en bloc. Cada pessoa incorpora o ser homem ou mulher de maneira própria e pessoal.

Diversas etnografias recentes mostram que, geralmente, o sangue masculino é considerado mais grosso, mais escuro, mais quente e condutor de pensamentos mais fortes do que o sangue feminino, devido ao fato de que o trabalho masculino exige maior coragem para enfrentar 
Belaunde, L. E. A força dos pensamentos, o fedor do sangue...

perigo do que o das mulheres. Mas isso depende do trabalho de fato realizado por cada homem individualmente. A visão das veias de um homem batendo de forma protuberante sob sua pele é uma prova de seus próprios pensamentos masculinos. Isso não implica que o sangue masculino seja melhor do que o feminino. Na verdade, significa que as pessoas atribuídas de gênero têm o tipo de sangue correspondente a seus próprios espíritos, trabalho e pensamentos pessoais. Além disso, mulheres muito trabalhadeiras podem ter mais força no sangue do que muitos homens - certamente mais do que os habitantes das cidades, que ficam sempre sentados atrás de uma mesa! (Colpron, 2004, p. 202; Goulard, 1998, p. 119; Surrallés, 1999, p. 103). Seria possível argumentar que "vitalidade" é um termo mais adequado para descrever os conceitos indígenas. Sugiro, no entanto, que vitalidade e força se referem a duas noções diferentes, embora intimamente relacionadas. Vitalidade se refere a espíritos, almas e nomes que infundem vida, conhecimento e força ao sangue (ver Rosengren e Santos-Granero, neste volume); enquanto força é mais especificamente a habilidade de desempenhar um trabalho habilidoso que exige disciplina e suor, ou seja, agüentar "sofrimento", como dizem os povos amazonenses ao falar em espanhol ou português. A força é, portanto, uma demonstração crucial da vitalidade espiritual. Essa idéia torna-se clara, por exemplo, nas palavras uitoto de conhecimento rafue. O rafue dos homens, em infusão com a vitalidade espiritual da coca e do tabaco, é, no entanto, nada mais além de "estórias" bakaki, a menos que façam "emergir a realidade" com o sofrimento e o suor do trabalho de uma pessoa (Candre \& Echeverri, 1993, p. 162; Echeverri, 2000, p. 43). O suor é a "via de nascimento", tanto nascimento de produtos quanto nascimento de crianças. Como explicam as mulheres yine, "fazer força”, suar e lidar com a dor por si mesmas são as formas pelas quais as mulheres fazem com que os bebês venham ao mundo (Belaunde, 2003, p. 134). ${ }^{6}$ 
Revista de Antropologia, São Paulo, USP, 2006, v. 49 no 1.

No entanto, é exatamente a demonstração de força e pensamentos das mulheres durante o parto que mais marcadamente separa o seu sangue do sangue dos homens. Por toda a Amazônia, o sangramento pósparto é considerado de forma consistente como a forma de perda de sangue que traz maiores perigos espirituais para o pai, o bebê e a mãe, mas também para todos aqueles que compartilham a sua existência. A menstruação vem em segundo lugar - as etnografias indicam que o sangue menstrual é considerado uma forma de sangramento de pós-parto, na medida em que é freqüentemente atribuído a uma gravidez interrompida, e/ou purgação de sangue excessivo e/ou sujo, necessário para iniciar uma gravidez bem-sucedida. A menstruação certamente não é concebida como um processo orgânico que ocorre "naturalmente". Ela é produzida por outros, por meio de intervenção ritual ou manipulação física da genitália feminina, inclusive por meio do ato sexual. De fato, as idéias de que a relação sexual faz com que as mulheres menstruem, de que mulheres sexualmente inativas "secam" e de que o acúmulo no útero de grandes quantidades de sêmen - de um ou mais pais - é necessário para interromper a menstruação e completar a gestação são encontradas por toda a Amazônia (Reichel-Dolmatoff, 1997, p. 62; Albert, 1985, p. 580; McCallum, 2001, p. 17; Conklin, 2001b, p. 53; Rodgers, 2002, p. 107). A menstruação também é amplamente atribuída à troca de "pele/corpo" da mulher e a seu sincronismo com os ciclos da lua.

Entre os grupos culturais, bem como dentro de um grupo cultural, homens e mulheres detêm diversos entendimentos da menstruação, não necessariamente consistentes ou integrados. Infelizmente, há poucos estudos etnográficos sobre esse assunto específico. No entanto, o ponto que quero enfatizar aqui é de que a evidência disponível indica que as visões amazônicas fazem ligações processuais entre menstruação, gravidez, parto, lactação, contracepção e (possivelmente) aborto. Metodologicamente, isso implica que um estágio do processo precisa ser entendido 
Belaunde, L. E. A força dos pensamentos, o fedor do sangue...

com relação a outros (Belaunde, 1997). Para conseguir apreender o significado do sangramento menstrual ou pós-parto, deve-se portanto inserir o sangramento no processo de gestação: a gestação torna-se uma possibilidade em potência com a menstruação, ela se torna realidade com o acúmulo de sêmen no útero, e é encerrada com o sangramento pósparto. Ou seja, o sangramento marca tanto o começo quanto o final da gestação, quer dizer, de um processo de desdobramento implicado na geração de um novo ser. De fato, por toda a Amazônia, o sangue menstrual das mulheres e o sangramento pós-parto são concebidos como perigosos processos de desdobramento que efetuam uma "troca de pele/ corpo"' 7

Para avançar o estudo do sangramento, deve-se portanto recorrer aos mestres do desdobramento na Amazônia: as cobras e a lua. Por toda a Amazônia, o sangramento está ligado à relação íntima das mulheres com as anacondas. A anaconda é mestre de desdobramento, já que tem a língua e o pênis bifurcados, pode viver na água, além de viver na terra e em árvores (Lagrou, 1998, p. 241), e se identifica com o arco-íris cósmico e a serpente subaquática, considerada "mãe" ou "dona" de todas as cobras. Como as cobras, as mulheres mudam de pele/corpo e produzem substâncias venenosas. Seu veneno, segundo Guss (1990, p. 67) argumenta para os Yekuana, é "o mais tóxico e selvagem de toda a cultura”. Mas, para um povo da floresta tropical acostumado a tirar seu sustento por meio do uso habilidoso de venenos, a menstruação é um presente precioso. Mais do que qualquer outro veneno utilizado no modo de vida yekuana - veneno de caça, veneno de pesca, mandioca-brava, substâncias psicotrópicas de origem animal e vegetal etc. -, o sangramento das mulheres causa as transformações mais dramáticas e exige os processamentos mais cautelosos. Tem também o poder de tornar outros venenos ineficientes - uma idéia sustentada por diversos grupos étnicos. 
Revista de Antropologia, São Paulo, USP, 2006, v. 49 no 1.

Venenos de caça e pesca, e mesmo venenos de cobras, estragam com a menstruação (Brown, 1985, p. 65). A cerveja de mandioca fica estragada e perigosa. Ferramentas, materiais, espingardas, cestas e armadilhas de pesca tornam-se inúteis. Caçadores erram os tiros e tornam-se irritadiços (Lima, 1995, p. 203; Rivas, 2004, p. 15). Xamãs também são afetados. Podem ter dores de cabeça, hemorragias nasais, baço inchado e não conseguem contatar divindades. Ao contrário, durante as sessões xamanísticas, atraem os espíritos sedentos de sangue e têm "viagens" enlouquecedoras (Arévalo 1986, p. 155; Fausto, 2001, p. 342; Belaunde, 2001, p. 53). Em geral, a contaminação com o sangue de uma mulher é considerada uma das maiores causas de doença (Garnelo, 2003). Segundo os Macuna, o cheiro do sangue de uma mulher "mata os pensamentos das pessoas", poluindo seus "ouvidos" com calor e tornando as pessoas nervosas (Mahecha, 2004, p. 6; Århem et al, 2004, p. 207). Em outras palavras, o sangue que sai do corpo das mulheres afeta o sangue que circula dentro dos corpos de homens e mulheres e destrói a capacidade de conduzir espíritos, pensamento e força para todas as partes do corpo. Utilizando a expressão dos Macuna, seria possível argumentar que o sangue derramado pelas mulheres "é um assassino de pensamentos" e da agência habilidosa, e portanto é altamente negativo. Por outro lado, ao mesmo tempo, a observância de dieta e reclusão limpa reinicia o fluxo de sangue, tornando-o mais forte e mais cheio de pensamentos. Também dá às mulheres vidas mais longas que as dos homens (C. HughJones, 1979).

A transformação bem-sucedida das mulheres quando estão sangrando depende da observância de restrições estritas, sozinhas principalmente, mas também acompanhadas pelos companheiros. Mulheres em sangramento geralmente interrompem todas, ou pelo menos algumas, tarefas diárias e observam um período de abstinência sexual, comendo 
Belaunde, L. E. A força dos pensamentos, o fedor do sangue...

apenas alimentos considerados "suaves", tais como vegetais e a carne de animais e peixes que se considere ter "pouco sangue". Sua dieta exclui a carne de animais que se considere ter "muito sangue", tais como a anta. As mulheres também evitam ir ao rio ou à floresta, tocar qualquer item da cultura material ou se aproximar dos homens. As restrições são enfatizadas principalmente durante a celebração da primeira menstruação de uma menina ou após o parto, mas também são observadas um pouco menos todas as vezes que o sangramento menstrual e/ou pós-parto ocorre. Atualmente, entre muitos grupos étnicos, há uma tendência a abandonar essas práticas, bem como outras práticas reprodutivas tais como os métodos de contracepção e o espaçamento dos nascimentos (Belaunde, 2005, p. 141; Mahecha, 2004, p. 162). Até recentemente, no entanto, a puberdade feminina era revestida do mais alto significado social entre muitos grupos étnicos e era celebrada em reunióes especiais de toda a rede de parentesco (Gow, 1999, p. 235; Valenzuela \& Valera, 2005, p. 60; Guss, 1990, p. 165).

Os homens ficavam totalmente envolvidos com a organização da festa e eram também considerados responsáveis ritualmente por cuidar das mulheres sempre que estivessem reclusas. Entre os Macuna, até hoje, curadores masculinos são responsáveis pelo fornecimento de pintura corporal vermelha, cantada ritualmente carayurú (Bigmonia chica), para cobrir o cheiro da "pele descascada" das mulheres com um halo de invisibilidade espiritual, protegendo-as para que não atraiam os espíritos sedentos de sangue. ${ }^{8}$ Meninas que estudam longe de casa regularmente recebem encomendas especiais de carayurú cantado, enviadas por seus pais que ficaram na aldeia. Freqüentemente os homens cozinham e cuidam de suas famílias enquanto as suas esposas permanecem no confinamento (Mahecha, 2004, p. 170; Århem et al, 2004, p. 210). O sangramento das mulheres, portanto, cria uma arena onde o equilíbrio das relações de poder e interdependência entre homens e mulheres se realiza. 
Revista de Antropologia, São Paulo, USP, 2006, v. 49 no 1.

De todos os aspectos relacionados com o sangramento de uma mulher, a subordinação ritual das mulheres aos homens é a única que gerou uma abundância de escritos antropológicos. As narrativas míticas amazonenses que explicam a origem da menstruação como oriunda de uma mudança de poder, expressa por exemplo em estórias sobre como originalmente os homens, e não as mulheres, sangravam, são apresentadas por diversos antropólogos para apoiar o argumento de que as mulheres têm um status subordinado na sociedade. No entanto, alguns autores defendem que a subordinação ritual das mulheres não se traduz claramente na vida diária (Murphy \& Murphy, 1974; Ladeira, 1997; Garnelo, 2003; Franchetto, 1999; Lasmar, 2002; Jackson, 1992; Coimbra \& Garnelo, 2003). Quer as narrativas míticas sejam ou não índices da hierarquia masculina, é inegável que essas narrativas insistem em atribuir categoricamente o sangramento às mulheres, portanto sancionando a imposição de restriçôes severas a elas. Mas é também verdade que as mesmas narrativas atribuem aos homens a difícil responsabilidade de "sarar o mundo" e tomar conta de mulheres em sangramento num cosmos cheio de perigos e vinganças. ${ }^{9}$

Portanto, ao invés de ler essas narrativas como simples índices de subordinação feminina, eu sugiro, seguindo os passos de Overing (1986), sua leitura como depoimentos sobre a atribuição de gênero aos corpos e às responsabilidades rituais. No repertório mítico de cada grupo étnico, as narrativas menstruais não estão isoladas, mas, ao contrário, pertencem a ciclos míticos mais amplos que contam sobre a aquisição progressiva de agências masculinas e femininas. Algumas narrativas contam da aquisição da menstruação, outras de genitália, outras de amamentação, outras contam como as mulheres aprenderam a dar à luz através da vagina, e assim por diante. No processo de aquisição de gênero, homens e mulheres se confrontam, impelidos pelos apetites por comida e sexo, progressivamente moldando seus corpos e adquirindo conhecimentos e responsabilidades. 
Belaunde, L. E. A força dos pensamentos, o fedor do sangue...

O mito piaroa sobre a origem da menstruação (ibid.) oferece um bom exemplo. Buok'a tinha um pênis tão longo que o carregava enrolado em torno dos ombros. As mulheres o adoravam, mas, ao invés de satisfazer o seu desejo, seu pênis lhes despertava um apetite insaciável por sexo. O marido delas, Wahari, o irmão mais novo de Buok'a, movido pelo ciúmes, cortou o pênis de Buok'a num tamanho menor, e as mulheres adquiriram a menstruação depois de copular com ele enquanto sangrava. Durante o sangramento, elas largavam o seu trabalho e Wahari "ficava com todo o trabalho sozinho". Wahari então decretou: "Os homens não devem menstruar, as mulheres devem”. Uma estória complementar se encontra na narrativa airo-pai sobre a vagina dentada (Belaunde, 2001, p. 63). As esposas de Ñañe, Lua, tinham um par de mandíbulas em suas vaginas, ameaçando de castração qualquer um que ousasse se aproximar delas. Lua usou as mandíbulas mordedoras de suas esposas para esculpir palmas em suas mãos e pés. Depois, com suas novas mãos, ele enrolou um pedaço de fibras Astrocaryum para fazer um barbante, e o utilizou para puxar as mandíbulas de suas esposas, causando-lhes sangramento. Essas duas narrativas, que alguns relacionam à ansiedade da castração (Gregor, 1985), são mais precisamente estórias sobre a modelagem mútua de corpos atribuídos de gênero e apetites moderados. Enquanto as mulheres piaroa eram famintas por sexo, as mulheres airo-pai ferozmente o rejeitavam. No final, Buok'a não é castrado, mas ganha um pênis de tamanho normal, e Lua transforma a ameaça de castração em ferramenta para obter mão e pés destros e para desarmar as vaginas ferozes. No entanto, tanto a narrativa piaroa quanto a airo-pai deixam claro que a aquisição de corpos atribuídos de gênero caminha passo a passo com o surgimento de rivalidade e vingança: a vingança de sangue.

$\mathrm{O}$ significado da vingança com relação às transformações provocadas pelo sangramento torna-se claro quando consideramos que os ciclos das 
Revista de Antropologia, São Paulo, USP, 2006, v. 49 no 1.

mulheres estão intimamente associados à lua. A lua governa as marés e o fluxo de todos os líquidos, incluindo o sangue, quando percorrem os meandros de rios e veias semelhantes a serpentes. Na cosmologia e mitologia amazonense, Lua é um dos principais personagens, com freqüência explicitamente associado num par à Anaconda, como na figura Cashinahua de Yube, "Lua/Cobra" (Lagrou, 1998, p. 240). No entanto, a figura de Lua tem sido retirada da maioria dos debates teóricos em antropologia. Uma lacuna importante existe, em particular, com relação ao tema mítico encontrado na Amazônia, que pode ser chamado de estória do incesto de Lua. Nessa estória, Lua é uma figura masculina incestuosa. Em outro lugar (Belaunde, 2005), tento começar a preencher essa lacuna desenvolvendo uma análise comparativa do tema. Com humor amazonense infalível, inúmeras narrativas - sejam pequenas narrativas separadas ou partes de narrativas mais longas - referem a origem do sangramento feminino a uma relação incestuosa entre Lua e sua irmã. ${ }^{10}$ Tipicamente, as estórias são assim. Lua visita sua irmã à noite, escondendo sua identidade no escuro. Querendo descobrir quem era seu amante, ela mancha o rosto dele com tinta preta (Genipa americana). As façanhas incestuosas são reveladas quando, sob a luz do dia, ela reconhece sua própria marca na face dele. Lua então é envergonhado e/ ou morto, geralmente por decapitação, literalmente perdendo seu rosto e colocando sua cabeça cortada no céu como lembrança de seu feito. A versão sharanahua relatada por Siskind oferece um bom exemplo.

Escuta, eu vou te contar, diz Basta. Na escuridão, Lua fez amor com sua irmã. Era noite e ele continuava fazendo amor com ela. Ela queria saber quem era seu amante, então, no escuro, ela pintou metade de seu rosto com jenipapo preto. No dia seguinte, ela viu os homens seguindo a trilha. De repente ela viu o homem. "Não, não pode ser, é meu irmão mais velho 
Belaunde, L. E. A força dos pensamentos, o fedor do sangue...

quem tem jenipapo em um dos lados da cara!" - "Que você morra!", diz ela. "Que um forasteiro (nawa) mate você!” Ele correu de sua irmã brava, chorando... (Siskind, 1973, p. 46)

Como argumento em outro lugar (Belaunde, 2005, p. 261-80), as inúmeras variações da estória do incesto e da morte de Lua encontradas pela Amazônia têm como fio condutor comum a busca pelo conhecimento: o desejo de saber quem é o amante, o desejo satisfeito por meio do primeiro ato de escrita de uma mulher que trouxe a morte de Lua. Antes de partir para o céu, Lua deixa o sangue de sua morte como lembrança para as mulheres e vingança pelo fato de uma mulher ter escrito a sua palma no rosto dele. Diversas versões da estória afirmam que, depois do sangramento, as barrigas das mulheres cresciam com a gravidez, portanto, relacionando diretamente a menstruação ao início da gestação. Lua, brilhando no céu noturno com a escrita do incesto em sua face, é a lembrança da morte do pai primordial rompendo a escuridão e a ignorância da noite, e impondo sua vingança sobre os vivos no sangue derramado pelas mulheres na menstruação e no parto. A vergonha e morte de Lua criam a condição sine qua non para a existência de parentesco ao longo do tempo: memória. A memória do incesto primordial atualizada na vida diária no sangue derramado pelo qual as crianças nascem.

Com base nessas narrativas, evidencia-se que as diferenças entre os sangues de homens e mulheres refletem seu conhecimento diferenciado de Lua e do incesto. De fato, entre diversos grupos étnicos, quando as mulheres sangram, diz-se que elas "vêem Lua", reatualizando, no fluxo do seu sangue, os eventos míticos do incesto e da vingança de Lua. ${ }^{11}$ No entanto, o sangue das mulheres raramente recebe atenção no paradigma dominante do incesto estabelecido pela teoria da aliança, tal como em Mythologiques de Levi-Strauss (1964, p. 318) e na etnografia sharanahua de Siskind. Exceto pelos estudos dos Barasana (C. Hugh-Jones, 1979; 
S. Hugh-Jones, 1979), a ênfase é posta quase unilateralmente sobre o estabelecimento das relações de troca de mulheres entre afins masculinos, conseqüentemente a condenação do incesto. Infelizmente, para a maioria dos antropólogos, o sangue das mulheres não é o pedaço interessante da estória.

Minha leitura da estória do incesto de Lua tem por objetivo compreender o que é o sangue, e para isso é preciso tomar um pouco de distância do caminho habitual da teoria da aliança e buscar inspiração numa visão amazonense, seguindo as explicações apresentadas por Tomás Román, líder uitoto da Colômbia. Numa palestra proferida em novembro de 2004, na Universidade Leticia, ele explicou em espanhol que os animais, referindo-se a mamíferos terrestres, particularmente queixadas, foram pessoas nos tempos míticos e eram semelhantes ao povo uitoto, na medida em que eles tinham líderes e se organizavam em grupos durante suas perambulações pela floresta. No entanto, diferiam dos Uitoto porque: "Eles não se lembram de seus parentes. Quando crescem, não reconhecem mais os seus pais. É por isso que cometem incesto" (Belaunde, 2005, p. 255).

Seguindo as explicações de Tomás Román, sugiro que a estória do incesto de Lua seja um mito sobre como a memória torna possível que as mulheres separem irmão de cônjuge. No sangramento, as mulheres confirmam, de forma corporificada, seu conhecimento do incesto e sua habilidade de reconhecer seus parentes. Portanto, o mito coloca uma diferenciação entre irmãos e cônjuge de um ponto de vista feminino, e não masculino, como proposto pela teoria da aliança. Mas é claro que a minha interpretação não se opõe às conclusões sobre a centralidade da troca matrimonial da teoria da aliança, ao contrário, complementa essa teoria oferecendo uma visão de como o sangue é ligado ao incesto, ao gênero e ao conhecimento. 
Belaunde, L. E. A força dos pensamentos, o fedor do sangue...

O sangramento é uma capacidade feminina de conhecimento, implicando conseqüências sociais das mais significativas, e pode ser visto como um poder feminino, ao invés de um índice da subordinação feminina. Ao mesmo tempo, o conhecimento do sangramento não é conferido unicamente às mulheres, já que os homens também nascem do sangue vertido por elas e podem também sangrar e causar sangramento a si mesmos e a outros. Embora banido do meio dos vivos, o incesto primordial de Lua é a instância fundadora do parentesco humano, já que impõe o domínio da memória. Ou seja, ele impõe o domínio do conhecimento duradouro. Ou melhor, o domínio do conhecimento volta - ele não se perde - assim como a lua encontra seu caminho de volta ao céu, ou como nós encontramos o caminho de volta à consciência, lembrando e reconhecendo os parentes e o ambiente ao acordar pela manhã. Deve ser apontado que, em diversas línguas amazonenses, a palavra "lua" é polissêmica e, entre outros significados, traduz-se por "tempo/estação" (Reichel-Dolmatoff, 1997, p. 65). O incesto e a morte de Lua, portanto, estabelecem os tempos da memória humana.

A idéia é importante para as concepções amazonenses de conhecimento, já que, como argumentei, nas línguas amazonenses o "pensamento" significa lembrar de nossos parentes, sentir saudades deles e agir no sentido de lhes oferecer cuidados e sustento. A habilidade de reconhecer nossos parentes, inscrita no fluxo sangüíneo governado por Lua, é determinante do pensamento humano e seu exercício nas atividades produtivas diárias. Além disso, o incesto e a morte de Lua permanecem presentes na vida cotidiana e nas crianças geradas. Periodicamente, o sangue que as mulheres derramam durante a menstruação e o pós-parto renova os episódios da vingança de Lua. Relações incestuosas e não incestuosas coexistem portanto, assim como as realidades míticas e cotidianas também coexistem. As crianças nascem da relação sexual das mulheres com 
os homens - que são os pais não incestuosos de seus filhos - e com Lua - que é o pai primordial de seus filhos: pai incestuoso e morto. ${ }^{12}$

Embora o sangramento das mulheres seja a forma mais evidente de "troca de pele/corpo", os homens também podem passar por transformações semelhantes. $\mathrm{Na}$ área do Xingu, por exemplo, os meninos na puberdade soltam sangue das orelhas como um meio de ampliar suas capacidades de audição e entendimento moral. Retenção ou perda excessiva de sangue, calor ou frio é considerado prejudicial, o sangramento é utilizado portanto como técnica para administrar a saúde dos homens ao longo de suas vidas. A escarificação, particularmente, com freqüência é praticada pelos lutadores para se tornarem fortes ou para expulsar sangue excessivo acumulado na barriga, que causa preguiça (Seeger et al, 1979). Sangue na barriga também afeta homens homicidas, pois se considera que "ingeriram” o sangue de suas vítimas ao matar. Diz-se que o sangue do inimigo penetra a barriga de seu assassino como vingança (Århem et al, 2004, p. 224; Lima, 1995, p. 132; Albert, 1985, p. 375; Conklin, 2001b, p. 161; Fausto, 2001, p. 467; Viveiros de Castro, 2003, p. 47). Etnografias de diversas regióes mostram que os povos amazonenses fazem paralelos explícitos entre o resguardo masculino do homicida e o resguardo feminino, menstrual e/ou pós-parto. Como Viveiros de Castro (2003) mostra, os rituais de resguardo do homicida revelam a feminização dos homens homicidas, na medida em que o assassino que sofre a vingança do sangue de seu inimigo está de certa forma impregnado dele e, espiritualmente, preso ao cadáver da vítima e a seu destino pós-morte. Depois de observar um período de dieta e reclusão, o assassino emerge do confinamento revestido de novo corpo, espíritos e conhecimento, pronto para recomeçar a comer, trabalhar, manter relações sexuais e gerar uma criança por meio da transformação do sangue de seu inimigo em seu próprio sangue. 
Belaunde, L. E. A força dos pensamentos, o fedor do sangue...

A feminização do assassino, devemos enfatizar, não significa que os homens homicidas possam transformar-se em mulheres como punição por não terem observado as restrições do resguardo (Belaunde, 2005, p. 187). Na verdade, ela salienta o fato de que homens homicidas "parecem mulheres", tomando emprestada a expressão utilizada pelos AiroPai e por diversos outros grupos étnicos, na medida em que o sangramento opera um desdobramento semelhante à "troca de pele/corpo" das mulheres durante o sangramento menstrual ou pós-parto. A associação inextricável entre sangrar e ser mulher não é surpreendente, dado que está proclamada na mitologia amazonense de muitas formas. Sangrar implica estar na posição feminina e sofrer vingança, o que é necessário para fertilidade e renovação. Homens homicidas não sangram seu próprio sangue, pode-se argumentar. É o "sangue de seus inimigos". Mas as mulheres também não sangram o seu próprio sangue. Elas sangram o sangue de Lua. Tanto homens homicidas quanto mulheres se encontram sob a vingança do sangue de seu inimigo e vulneráveis a perigos semelhantes. Para se proteger desses perigos e processar adequadamente o sangue de seus inimigos para renovação e fertilidade, eles precisam observar rituais semelhantes de resguardo: dieta e reclusão.

A lista real de perigos que pendem sobre os homens homicidas e as mulheres em período de sangramento que quebram as restriçōes do resguardo varia de grupo étnico para grupo étnico. Alguns são mais severos do que outros, incluindo ameaças meteorológicas, como a ocorrência de enchentes, ventos e escuridão, e ameaças pessoais, tais como má postura, preguiça, gula, envelhecimento precoce, doença, loucura, sedução ou abdução por espíritos, gravidez por espíritos e morte (Århem et al, 2004; Lima, 1995; Albert, 1985; Conklin, 2001b; Fausto, 2001; Viveiros de Castro, 2003; Reagan, 2003). Uma idéia em comum percorre todos esses perigos: enquanto estão "trocando de pele/corpo", homens e mulheres ficam suscetíveis de passar por uma transformação des- 
controlada que os transformaria em "outros" e os alienaria de seus parentes, seja parcialmente ou completamente. Na pior das possibilidades, essa alienação os mataria ou os tornaria totalmente incapazes de reconhecer seus parentes, ficando perdidos (Belaunde, 2005, p. 187).

A seguir, palavras de curadores macuna:

Uma mulher está trocando de pele com a menstruação; é por isso que ela não pode ir à floresta ou ficar sob o sol ou ir ao rio [...]. Se ela caminha perto do rio, um vento forte começa; nas árvores há uma espécie de talo chamado butuasena que desce para a terra e toma a forma de um animal qualquer. Eles descem das árvores para atacar a mulher em seu período de menstruação e podem levá-la para sua casa; nesse momento a mulher fica louca ao ver como os animais saem de todos os lugares para raptá-la. (in Århem et al, 2004, p. 211-3)

Em muitas partes da Amazônia, considera-se que o sangue derramado, e particularmente o seu cheiro, tem um poder transformador sobre a experiência vivida semelhante ao das substâncias psicoativas, abrindo as cortinas da percepção e comunicação que geralmente separam a experiência cotidiana da experiência de "outros" espaços-tempos cosmológicos. Mas, diferente das plantas psicoativas, o cheiro do sangue não permite estabelecer também a comunicação com os espaços-tempos divinos para objetivos de cura. Ele apenas introduz espaços-tempos de multiplicidade transformadora incontroláveis, quando/onde os espíritos de plantas/animais tomam a forma humana - como ocorre durante os espaços-tempos míticos primordiais - e se vingam dos humanos, seduzindo ou raptando os que se tornam perceptíveis pelo cheiro de sangue, tornando-os diferentes de si mesmos, alienados, doentes ou mortos, ou seja, perdidos para seus parentes. 
Belaunde, L. E. A força dos pensamentos, o fedor do sangue...

A ligação entre o efeito alienador do cheiro do sangue e a separação entre os espíritos de animais/plantas e os homens, narrada em mitos por toda a Amazônia, fica mais clara quando lembramos o que significa "se perder" para os povos amazonenses. Como Varese (1973) indica para os Asháninka, perder-se e perder todo o conhecimento pessoal são duas possibilidades bastante reais na vida cotidiana dos povos da floresta.

A mesma expressão usada em mitos para indicar a transformação de pessoas em animais é utilizada na linguagem cotidiana para indicar a possibilidade de se perder na floresta, uma eventualidade bastante freqüente [...]. O conhecimento salva, a ignorância faz com que você se perca. (Varese, 1973, p. 82)

A equação traçada pelos Asháninka entre o conhecimento e a capacidade de reconhecer uma trilha para voltar para casa e se reencontrar com a família sugere, como Tomás Román fala sobre os Uitoto, que uma diferença-chave entre os Asháninka e os animais é a capacidade de reconhecer, de lembrar. Os animais, assim como as pessoas que se perdem na floresta, são incapazes de reconhecer seus parentes humanos e, portanto, eles existem num espaço-tempo fora da memória humana, como Lua incestuoso e sua irmã ao copularem. Pode ser este o destino também daqueles homens e mulheres que não observam corretamente o resguardo do sangramento.

Os rituais homicidas asháninka ilustram bem a alienação que pende sobre os homens impregnados com o cheiro de sangue de seus inimigos (Regan, 2003). Para o mironti, um espírito com forma de anta que tem uma percepção invertida dos gêneros, os homens homicidas são mulheres atraentes, que ele seduz nos sonhos, quando aqueles estão dormindo. Por esse motivo, é crucial que os homens assassinos permaneçam acordados durante o período de resguardo. Se um assassino dormir, ele 
Revista de Antropologia, São Paulo, USP, 2006, v. 49 no 1.

cai no feitiço e na visão de mundo de mironti, sendo engravidado por ele e dando à luz macacos e lagartos. Loucamente apaixonado, o assassino perde as lembranças de seus parentes, fugindo deles e chorando pelo amor de mironti. A única estratégia para afugentar um mironti é jogarlhe leite materno, pois, em sua percepção invertida de gênero, o peito de uma mulher são testículos enormes que o apavoram. $\mathrm{O}$ assassino, no entanto, talvez nunca recupere a memória de quem era antes de cair no feitiço. Alguns poderiam argumentar que esse entendimento ritual destaca a extrema feminização do assassino. No entanto, o assassino seduzido pelo mironti não se torna uma mulher asháninka, mãe de crianças asháninka. Ele se torna um ser alienado, incapaz de reconhecer seus parentes e mãe de monstros.

Entre os Asháninka e vários outros grupos étnicos, uma ameaça semelhante de fertilidade alienada pende sobre as mulheres em sangramento. Proliferam estórias sobre mulheres que, quebrando o seu resguardo menstrual, foram à margem do rio, caíram no feitiço dos botos e deram à luz crianças-boto. Diz-se que algumas mulheres ficam loucas, irreversivelmente perdendo a memória de seus parentes e se afogando pelo amor de um boto. Em várias partes da Amazônia, tanto rural quanto urbana, crianças de pais desconhecidos - um estado social praticamente inexistente num passado recente - são chamadas de "filhos de boto" e, se têm pele clara, são consideradas "filhas do boto-vermelho", porque os botos-vermelhos são considerados espíritos de "brancos" mortos. A figura do boto foi portanto readaptada para dar conta da atual quebra de responsabilidades paternas, da mestiçagem populacional e da sedução exercida por "brancos", seus estilos de vida e seu dinheiro, e a desilusão que geralmente acompanha relações com "outros" tão cheios de truques e evasivas (Cárdenas, 2005, p. 6; Gonçalves, 2001, p. 371; Slater, 1994, p. 202; Valenzuela \& Valera, 2005, p. 43; Lasmar, 2002, p. 28; Regan, 1983, p. 80). 
Belaunde, L. E. A força dos pensamentos, o fedor do sangue...

Os aspectos da hematologia amazonense reunidos neste ensaio revelam o que poderia ser chamado uma teoria transcultural "réptil" do sangue articulada com a noção de "troca de pele/corpo", chave para a cosmologia e o xamanismo perspectivista amazonense. Se, como Viveiros de Castro (1996, p. 128) argumenta, o corpo é o local das perspectivas, então, sugiro que o sangue é um operador de perspectivas. Na Amazônia, o sangue é uma substância psicoativa, provavelmente a mais forte. Ele leva pensamento e força e incorpora os espíritos e o conhecimento de uma pessoa, trazendo de volta à memória o conhecimento de si e dos parentes, mantendo a vida. $\mathrm{O}$ sangue tanto une quanto divide os seres humanos em homens e mulheres. Em primeiro lugar, porque o sangue transporta conhecimento corporificado, atribuindo gênero à pessoa; em segundo, porque o sangramento é explicitamente uma posição feminina, embora ela não seja ocupada apenas por mulheres. O sangramento das mulheres é uma memória da morte e do incesto de Lua, a instância primordial em que se fundam a memória, o parentesco e a fertilidade, que derivam da manipulação adequada da agência transformadora da vingança de Lua. Os homens também podem "parecer mulheres" quando se encontram sob a vingança do sangue de seus inimigos, semelhante ao sangramento das mulheres sob a vingança de Lua. O sangramento é, pode-se dizer, uma prerrogativa feminina compartilhada por ambos os gêneros, porque ambos são férteis, e o sangramento é a possibilidade de fazer surgir outros seres (Gonçalves, 2001, p. 233). Mas é uma possibilidade que precisa ser administrada com cuidado para alcançar fertilidade, oferecendo continuidade à memória humana. $\mathrm{O}$ cheiro do sangue, denunciando o sangramento mesmo quando ele não pode ser visto ou tocado, põe em movimento a multiplicidade transformacional da vingança de "outros" espaços-tempos cosmológicos, trazendo o perigo de perda da memória humana, semelhante à perda de humanidade narrada em mitos onde/quando pessoas foram transformadas em animais/plantas. 
Tendo em vista o lugar de destaque do sangramento na cosmologia, sugiro que o xamanismo amazonense deveria ser caracterizado como complexo xamanístico reprodutivo. Estudar o xamanismo, como se ele existisse fora das práticas de administração do sangue de homens e mulheres, seria uma amputação da sua amplitude. ${ }^{13}$ Mesmo quando as mulheres não freqüentam as sessões xamânicas, o que muitas vezes é o caso devido às restriçôes que se lhes colocam por causa do sangramento, elas administram o fluxo do seu sangue junto com seus parceiros. Os homens não podem praticar o xamanismo quando carregam o cheiro de sangue nem o de sêmen, um derivado do sangue. A administração conjunta pelo casal de seu sangue implica conseqüências importantes para sua vida reprodutiva (Reichel-Dolmatoff, 1997, p. 65). Além disso, entre diversos grupos étnicos, as mulheres conhecem uma variedade de técnicas para administrar o fluxo de seu sangue, adquirem sabedoria xamanística, freqüentam e lideram sessões xamanísticas quando elas "parecem homens", protegidas do risco de perda da memória humana, acarretada pela multiplicidade transformacional do cheiro do sangue (Belaunde, 2001; Colpron, 2004; Perruchon, 1997; Madder, 1997). Ser homem ou ser mulher não é uma dicotomia rigidamente definida. Emprestando as palavras de Overing, é uma questão de diferença dentro da igualdade, e igualdade dentro da diferença.

\section{Notas}

1 A pesquisa para este artigo foi financiada pela Coordenação de Aperfeiçoamento de Pessoal de Ensino Superior (CAPES, Brasil) e pelo Instituto de Saúde Coletiva (ISC) da Universidade Federal da Bahia. Sou grata a Fernando Santos-Granero e George Mentore, por seus comentários e pela organização da edição deste volume, e a Emilia Sanabria, pela revisão do meu inglês. Agradeço a Joanna Overing e 
Belaunde, L. E. A força dos pensamentos, o fedor do sangue...

Napier e a todos os seus alunos, com os quais compartilhei momentos agradáveis de discussão.

2 Estou me referindo ao artigo da autora "Men Control Women? The Catch-22 in Gender Analysis".

3 Para comparação, em Iquito, uma língua záparo do Peru, o conceito indígena de pensamento é expresso por saminijuuni, "estar preocupado com alguém", e tar $++n i$, "sentir saudades quando ausente". É interessante que "preparar comida "é saminiini, evidenciando a ligação entre o pensamento e a provisão de alimentos (Bier \& Lev 2004; Sullón, 2005, p. 9).

4 Ver Santos-Granero, neste volume, sobre modos não corpóreos de conhecimento.

5 Observar dieta e reclusão com alguém é uma reafirmação de laços de parentesco (Da Matta, 1976). Durante a gestação, parto e pós-parto, a dieta e a reclusão são úteis na construção da paternidade responsável do homem com relação ao feto e à mãe (Ladeira, 1997; Rival, 1998; Belaunde, 2005, p. 271).

6 Em Iquito, $m+r a$, "crianças", e $m+r++n i$, "gerar, ter filhos", estão semanticamente relacionados a $m+r+$ taani, "agüentar, suportar em esforço"; $c u t++n i$ é "nascer", cut $++t++n i$, "cuidar de parturientes", e cut $t++n i$, "alvorecer" (Sullón, 2005, p. 7; Huamancayo, 2005, p. 8).

7 Em Iquito, $Q u++$ raqui, "menstruação", é o radical do qual deriva qu+raani, "pelar, tirar a pele". Qu+racama é uma cabana usada pelas mulheres durante suas menstruaçōes e considerada um lugar perigoso - qu+rana significa perigo (Sullón, 2005, p. 5).

8 Idéias semelhantes sobre a pintura corporal vermelha (carayurú Bigmonia chica el ou achiote Bixa orellana) existem por toda a Amazônia (Vilaça, 1992, p. 67).

9 Segundo os Macuna, a menstruação ocorreu pela primeira vez quando machos ayabaroa, "Seres Vivos", roubaram as flautas yuruparí de Rõmi Kumu, da "Mulher Curadora do Mundo". Conseqüentemente, ela os amaldiçoou assim: "Já que vocês roubaram 'aquela coisa' de mim, mesmo que vocês sejam bons curadores e tenham bastante conhecimento, vocês viverão tendo problemas com outras pessoas, até o fim do mundo" (Mahecha, 2004, p. 158). Durante os rituais de puberdade masculina yuruparí, os meninos são submetidos a resguardos semelhantes aos que envolvem o sangramento das mulheres e dos homens homicidas. Se quebrarem a dieta ou a reclusão, eles podem engravidar de um yuruparí, enlouquecer e/ou morrer (Århem et al, 2004, p. 224). 
10 No fascinante texto "O sexo dos astros", Lévi-Strauss (1973, p. 203) menciona comparativamente mitos americanos sobre o incesto de Lua e Sol. O autor destaca o binarismo existente entre os astros, seja qual for o sexo deles e a relação entre eles, mas não estuda as implicações do incesto de Lua para as relações de gênero e para a concepção do sangue e da gravidez. A análise comparativa do significado social das variaçóes das estórias do incesto de Lua ainda precisa ser feita. Por exemplo, entre os Desana, a menina é filha de Lua (Reichel-Dolmatoff, 1997, p. 165). Entre os Iquito, ela é sua sogra (Huamancayo, 2005, p. 3). Entre os Uitoto (Belaunde, no prelo), o desejo da menina em conhecer a identidade de seu amante é instigado pela mãe, e, entre os Shipaia (Lévi-Strauss, 1964, p. 318), por seus irmãos não incestuosos.

11 Ouvir a estória do incesto de Lua tem um efeito performático sobre as mulheres e pode lhes causar sangramento, segundo informa Siskind (1973, p. 57) sobre os Sharanahua. Kensinger (1995, p. 35) também afirma que, a cada nova menstruação, "homens e mulheres são lembrados das conseqüências do incesto".

12 A paternidade múltipla (Beckerman \& Valentine, 2002) pode envolver diversos pais vivos, cujo sêmen é acumulado no útero da mulher, e também diversos espíritos e pais mortos. Lua não é o único pai espiritual encontrado na Amazônia. Por exemplo, entre os Shipibo, os filhos podem ter pais vivos e pais cháiconibo, espíritos celestes (Colpron, 2004, p. 267). Entre os grupos étnicos que praticam os rituais de resguardo homicida, os inimigos mortos contribuem na paternidade dos filhos de seus assassinos (Viveiros de Castro, 2003, p. 47; Fausto, 2001, p. 467). Entre os Pirahã, a gestação começa com o "medo" sentido pelas mulheres durante a menstruação, devido à vingança de animais com "muito sangue" mortos pelos caçadores (Gonçalves, 2001, p. 227).

13 As cobras e a lua também têm um lugar de destaque no xamanismo amazonense. Entre os bebedores de ayahuasca (Banisteriopsis caapi), tais como os Kaxinawa, o ayahuasca é o sangue de Yube, "Lua/Cobra". Também é chamado nawa himi, o que significa "sangue do inimigo". O ayahuasca torna os que o bebem grávidos de mundos de imagens que emergem de suas barrigas (Lagrou, 1998, p. 98). 
Belaunde, L. E. A força dos Pensamentos, o fedor do sangue...

\section{Bibliografia}

ARÉVALO, Guillermo

1986 "El ayahuasca y el curandero shipibo-conibo del Ucayali (Perú)", América Indígena, XLVI(1): 147-62.

ALBERT, Bruce

Temps du sang. Temps des cendres. Représentations de la maladie, système rituel et espace politique chez les Yanomami du Sud Est (Amazonie Brésilienne), tese de doutorado, Université Paris X.

ÅHEM, Kaj; CAYÓN, Luisa; ANGULO, Gladis; GARCÍA, Maximiliano

2004 Etnografía makuna. Tradiciones, relatos y saberes de la Gente del Agua, Bogotá, Instituto Colombiano de Antropología e Historia.

BECKERMAN, Stephen \& VALENTINE, Paul

2002 Cultures of Multiple Fathers: The Theory and Practice of Partible Paternity in South America, Washington, Smithsonian Institute

BELAUNDE, Luisa Elvira

1997 "Looking After Your Woman. Contraception amongst the Airo-Pai (Secoya) of Western Amazonia", Anthropology and Medicine, vol. 4(2): 131-44.

2001 Viviendo bien: género y fertilidad entre los Airo-Pai de la Amazonía Peruana, Lima, CAAAP.

2003 "Yo solita haciendo fuerza: historias de parto entre los Yine (Piro)", Amazonía Peruana, vol. 28-29: 125-47.

2005 El recuerdo de luna: género, sangre y memoria entre los pueblos amazónicos, Lima, Universidad Mayor de San Marcos.

No prelo "Mujer. Cosmovisión Uitoto en la pintura de Rember Yahuarcani”, Boletín de la Maestría en Estudios Amazónicos 3, Lima, Universidad Nacional de San Marcos.

BIER, Christine \& LEV, Michael

2004 Estudios del idioma Iquito. Working Papers of the Iquito Language Documentation, manuscrito de projeto, Austin, University of Texas. 
Revista de Antropologia, São Paulo, USP, 2006, v. 49 no 1.

BROWN, Michael

1985

Tsewa's Gift. Magic and Meaning in an Amazonian Society, Washington, Smithonian Institution Press.

CANDRE, Hipólito \& ECHEVERRI, Juan Alvaro

1993

Tabaco frío. Coca dulce. La palabra del anciano Kinerai de la tribu Cananguchal para sanar y alegrar el corazón de sus huérfanos, Bogotá, Colcutura

CÁRDENAS, Flor

2005

"Sangre: connotación de vida, rituales y peligro entre los pueblos amazónicos", manuscrito inédito, Lima, Universidad Mayor de San Marcos.

COIMBRA, Carlos E. A. \& GARNELO, Luiza

2003

Questôes de saúde reprodutiva da mulher indígena no Brasil, Documento de trabalho 7, Rio de Janeiro, Fundação Oswaldo Cruz.

COLPRON, Anne Marie

2004 Dichotomies sexuelles dans l'étude du chamanisme: le contre exemple des femmes "chamanes" Shipibo-Conibo Amazonie Péruvienne, tese de PhD, University of Montréal.

CONKLIN, Beth

2001a "Women's Blood, Warrior's Blood and the Conquest of Vitality in Amazonia", in GREGOR, T. \& TUTZIN, D. (ed.), Gender in Amazonia and Melanesia: An Exploration of Comparative Method, Berkeley, University of California Press, pp. 141-74.

2001b Consuming Grief: Compassionate Cannibalism in an Amazonian Society, Austin, University of Texas.

CROCKER, Christopher

1985 Vital Souls. Bororo Cosmology, Natural Symbolism and Shamanism, Tucson, The University of California Press. 
Belaunde, L. E. A força dos Pensamentos, o fedor do SANGue...

DESCOLA, Phillipe

2001

"The Genres of Gender: Local Models of Global Paradigms in the Comparison of Amazonia and Melanesia", in GREGOR, T. \& TUZIN, D. (ed.), Gender in Amazonia and Melanesia: An Exploration of Comparative Method, Berkeley, University of California Press, pp. 91-114.

DESHAYES, Patrick \& KEIFENHEIM, Barbara

2003

Pensar el otro entre los Huni Kuin de la Amazonía Peruana, Lima, IFEA/CAAAP.

ECHEVERRI, Juan Álvaro

2000 "The First Love of a Young Man: Salt and Sexual Education Among the Uitoto Indians of Lowland Colombia", in OVERING, Joanna \& PASSES, Alan (ed.), The Anthropology of Love and Anger. The Aesthetic of Conviviality in Native Amazonia, Londres, Routledge, pp. 33-45.

FAUSTO, Carlos

2001 Inimigos fieis. História, guerra examanismo na Amazônia, São Paulo, Edusp.

FRANCHETTO, Bruna

1999 "Dossier mulheres indígenas", Estudos Feministas, vol. 7(1): 225-8.

GARNELO, Luiza

2003 Poder, hierarquia e reciprocidade: saúde e harmonia entre os Baniwa do Alto Rio Negro, Rio de Janeiro, Fiocruz

GONÇALVES, Marco Antonio

2001 mundo inacabado. Ação e criação em uma cosmologia amazônica. Etnografia Pirahã, Rio de Janeiro, UFRJ

GOULARD, Jean Pierre

1998 Le genre du corps, tese de doutorado, Paris, École des Hautes Études en Sciences Sociales.

GOW, Peter

1991

Of Mixed Blood: Kinship and History in Peruvian Amazonia, Oxford, Clarendon Press. 

the Royal Anthropological Institute, vol. 5(2): 229-47.

GREGOR, Thomas of Chicago Press.

GUSS, David

1990

Tejer y cantar, Caracas, Monte Ávila Editores.

GUZMÁN, Maria Antonieta

1997 Para que la yuca beba nuestra sangre. Trabajo, género y parentesco en una comunidad Quichua de la Amazonía Ecuatoriana, Quito, Abya-Yala.

HUAMANCAYO, Edinson

2005 "Las relaciones de género entre los antiguos iquito", manuscrito inédito, Lima, Universidad Mayor de San Marcos.

HUGH-JONES, Christine

1979 From the Milk River: Spatial and Temporal Processes in Northwest Amazonia, Cambridge, Cambridge University Press.

HUGH-JONES, Stephen

1979 The Palm and the Pleiades, Cambridge, Cambridge University Press.

JACKSON, Janet

1992 "The Meaning and Message of Symbolic Sexual Violence in Tukanoan Ritual", Anthropological Quarterly, vol. 65(1): 1-18.

KARADIMAS, Dimitri

1997 Le corps sauvage: idéologie du corps et représentation de l'environnement chez les Miraña de l'Amazonie Colombienne, tese de doutorado, Universidade Paris X.

KENSINGER, Kenneth M.

1995 How Real People Ought to Live. The Cashinahua of Eastern Peru, Prospect Heights, Waveland Press. 
Belaunde, L. E. A força dos Pensamentos, o fedor do SANGue...

LADEIRA, Maria Elisa

1997 "Las mujeres Timbira: control del cuerpo y reproducción social", in GONZALES MONTE, S. (ed.), Mujeres y relaciones de género en la antropología latinoamericana, México, Colegio de México, pp. 105-20.

LAGROU, Elsje

1998 Caminhos duplos e corpos. Uma abordagem perspectivista da identidade e alteridade entre os Kaxinawa, tese de doutorado, Universidade de São Paulo.

LASMAR, Cristiane

2002 De volta ao Lago de Leite. A experiência da alteridade em São Gabriel da Cachoeira (alto Rio Negro), tese de doutorado, Universidade Federal do Rio de Janeiro.

LÉVI-STRAUSS, Claude

1964 Mythologiques I. Le Cru et le Cuît, Paris, Plon.

1973 "Le sexe des astres", in Anthropologie Structurale Deux, Paris, Plon, pp. 251-62.

LIMA, Tânia Stolze

1995 A parte do caium. Etnografia Juruna, tese de doutorado, Museu Nacional, Universidade Federal do Rio de Janeiro.

LONDOÑO SULKIN, Carlos

2004 Muinane: Un proyecto moral a perpetuidad, Medellín, Editorial Universidad de Antioquia.

MADDER, Elke

1997 "Waimiaku: Las visiones y las relaciones de género en la cultura shuar", in PERRIN, M. \& PERRUCHON, M. (org.), Complementariedad entre hombre y mujer: las relaciones de género desde la perspectiva amerindia, Quito, Abya-Yala, pp. 23-46.

MAHECHA, Dany

2004 La formación de Masa Goro, personas verdaderas: pautas de crianza entre los Macuna del Bajo Apaporis, dissertação de mestrado, Universidad Nacional de Colombia. 
Revista de Antropologia, São Paulo, USP, 2006, v. 49 no 1.

MCCALLUM, Cecilia

2001

Gender and Sociality in Amazonia. How Real People are Made, Oxford, Berg.

MURPHY, Yolanda \& MURPHY, Robert

1974 Women of the Forest, New York/London, Columbia University Press.

OVERING, Joanna

1986 "Men Control Women? The Catch-22 in Gender Analysis", International Journal of Moral and Social Studies, vol. 1(2): 135-56.

OVERING KAPLAN, Joanna

1981 "Review Article: Amazonian Anthropology", Journal of Latin American Studies, vol. 13(1): 151-64.

PERRUCHON, Marie

1997

"Llegar a ser una mujer-hombre", in PERRIN, M. \& PERRUCHON, M. (org.), Complementariedad entre hombre y mujer. Relaciones de género desde la perspectiva amerindia, Quito, Abya-Yala, pp. 47-108.

REGAN, Jaime

Hacia la Tierra sin Mal: Estudio sobre la religiosidad del pueblo de la Amazonía, Iquitos, Centro de Estudios Teológicos de la Amazonía.

2003

"Mironti y los guerreros embarazados: relaciones de género en dos ritos Asháninka", Amazonía Peruana, vol. 28-29: 73-86.

REICHEL-DOLMATOFF, Gerardo

Chamanes de la selva pluvial, Londres, Themis Books.

RIVAL, Laura

1998

"Androgynous Parents and Guest Children: The Huaorani Couvades", Journal of the Royal Anthropological Institute, vol. 4(4): 619-42.

RIVAS, Roxani 2004

El gran pescador. Técnicas de pesca entre los Cocama-Cocamilla de la Amazonía Peruana, Lima, Pontificia Universidad Católica del Perú. 
Belaunde, L. E. A força dos Pensamentos, o fedor do SANGue...

RODGERS, David

2002 "A soma anômala: A questão do suplemento no xamanismo e menstruação Ikpeng", Mana, vol. 8(2): 91-125.

SEEGER, A.; DA MATTA, R.; VIVEIROS DE CASTRO, E.

1979 "A construção da pessoa nas sociedades indígenas brasileiras", Boletim do Museu Nacional, vol. XXXII: 2-19.

SISKIND, Janet

1973 To Hunt in the Morning, New York, Oxford University Press.

SLATER, Candance

1994 Dance of the Dolphin. Transformation and Disenchantment in the Amazonian imagination, Chicago, University of Chicago Press.

SULLÓN, Karina

2005 "Relaciones de género en la comunidad Iquito", manuscrito inédito, Universidad Nacional Mayor de San Marcos.

SURRALLÉS, Alexandre

1999 Au coeur du sens. Objectivation et subjectivation chez les Candoshi de l'Amazonie Péruvienne, tese de doutorado, École des Hautes Études en Sciences Sociales.

VALENZUELA, Pilar \& VALERAS, Agustina

2005

Koshi Shinanya Ainbo. El testimonio de una mujer Shipibo, Lima, Universidad Nacional Mayor de San Marcos.

VARESE, Stefano

1973[1968] La Sal de los Cerros. Una Aproximación al Mundo Campa, Lima, Retábulo de Papel.

VILAÇA, Aparecida

1992 Comendo como gente: formas do canibalismo Wari, Rio de Janeiro, Editora da UFRJ.

VIVEIROS DE CASTRO, Eduardo

1996

"Os pronomes cosmológicos e o perspectivismo ameríndio", Mana, vol. 2: 115-44.

2003

"La inmanencia del enemigo", Amazonía Peruana, vol. 28-29: 41-72. 
ABSTRACT: This paper lays the grounds for an Amazonian haematology aiming to unlock the significance of blood with relation to gender, knowledge, and cosmology. Drawing guidance from Overing's critique of patriarchy theory and her examination of Piaroa understandings of menstruation, it explores cross-cultural ideas about the embodiment and gendering of spirits, thought and strength in the blood, arguing that blood is conceived as a relationship for it transports knowledge to all body parts, both uniting and differentiating men and women, and constituting the pivot of a person's existence along his or her lifecycle. Through an examination of indigenous practices of diet and seclusion, it shows that blood management stands at the core of Amazonian health. Bleeding is a female prerogative and an embodied remembrance of the primordial incest between Moon and his sister, which founds human memory and kinship. Nevertheless, men may be "like women" when they find themselves under the revenge of their enemy's blood, similar to women under the revenge of Moon. Bleeding sets fertility in motion, opening the communication between daily and other cosmological time-spaces, and exposing both genders to the threat of transformational multiplicity, alienation and death. Its interlacing with shamanism is therefore fundamental.

KEY-WORDS: amazonian chamanism, menstruation, incest, blood, gender.

Tradução de Inês Rosa Bueno.

Aceito em fevereiro de 2006. 